\title{
Antimicrobial Efficacy of a Novel Irrigant, Nigella-Eugenia Oil Composite against Enterococcus faecalis and Candida albicans
}

\author{
Syed N Basheer ${ }^{1}$, Deepak K Sharma ${ }^{2}$
}

\begin{abstract}
Aim: The aim of this study was to develop a novel herbal irrigant Nigella-Eugenia oil composite (NEOc) and check its antimicrobial efficacy against Enterobacter faecalis and Candida albicans and compare it with standard chemical irrigants like sodium hypochlorite and chlorhexidine. Materials and methods: Soxhlet method was chosen to extract the content from Nigella sativa and Eugenia caryophyllus herbs. Minimum inhibitory concentration (MIC)/minimal bactericidal concentration (MBC)/minimal fungicidal concentration (MFC) of N. sativa and E. caryophyllus (ethanol extracts) against E. faecalis and C. albicans was determined by well diffusion method. A novel composite NEOc was developed and its antimicrobial activity was evaluated in terms of zone of inhibition around the wells in the inoculated Mueller-Hinton agar (MHA) plates and compared with sodium hypochlorite and chlorhexidine.

Results: About $300 \mu \mathrm{g} / \mathrm{mL}$ of test concentrate was selected as the MIC and MBC/MFC value for the test organism for both N. sativa and $E$. caryophyllus extracts. Antimicrobial activity of the extracts showed good inhibitory zones. The antimicrobial activity of NEOc against $E$. faecalis and C. albicans was found maximum of 21 and $22 \mathrm{~mm}$, respectively. The obtained results conformed the synergism behavior of two herbal extracts natively present in the developed composite. The cell viability percentage of the developed NEOc was more than $99 \%$ for all the test concentrations indicating its biocompatibility.

Conclusion: The developed novel NEOc's antimicrobial activity against E. faecalis and C. albicans was found to be slightly higher than $2.5 \%$ sodium hypochlorite and $2 \%$ chlorhexidine.

Clinical significance: The developed novel NEOc have the potential to be used as an alternative to chemical irrigants like sodium hypochlorite and chlorhexidine and decrease the incidence of endodontic treatment failures resulting from resistant bacteria like E. faecalis and C. albicans.

Keywords: Candida albicans, Enterococcus faecalis, Eugenia caryophyllus, irrigant, Nigella-eugenia oil composite.

World Journal of Dentistry (2022): 10.5005/jp-journals-10015-1902
\end{abstract}

\section{INTRODUCTION}

The main goal of endodontic treatment is elimination of microorganisms and their byproducts from the root canal system. ${ }^{1}$ Survival of microorganisms in the root-filled tooth is the cause of endodontic failure. According to Sjogren et al. for an effective and successful root canal treatment, the microbial infection needs to be eradicated before the root canal system is obturated. ${ }^{2}$ The persistence or penetration of microorganisms into the canal at the time of obturation leads to high risk of treatment failure. ${ }^{3}$

Several studies reported the prevalence of bacteria named Enterococcus faecalis ranging from 24 to $77 \%$ after endodontic treatment. ${ }^{4,5}$ The organism is a secondary bacterial invader that resisted intracanal antimicrobial procedures and survive as a monoculture, displays persistent periapical disease in treated root canals. ${ }^{6}$ Stuart et al. discussed the importance of Enterococcus faecalis in root canal treatment failure, as well as contemporary retreatment strategies. ${ }^{7}$ Möller et al. studied the influence of periapical tissues of indigenous microbial flora and recovered a significant pathogen, the yeast Candida albicans from persistent periapical lesions of root-filled teeth. ${ }^{8} \mathrm{Ng}$ also found hyphal-like structures which are suggestive of fungi in the interbacterial spaces. ${ }^{9}$

Endodontic infections caused by these group of organisms are currently treated by mechanical debridement along with chemical irrigants. ${ }^{10}$ Sodium hypochlorite $(\mathrm{NaOCl})$ is one of the most used irrigant in endodontic therapy. ${ }^{11}$ It is known for its antimicrobial action. The other functions of $\mathrm{NaOCl}$ include ability to partially
1,2Department of Conservative Dentistry and Endodontics, Faculty of Dentistry, Maharaj Vinayak Global University, Jaipur, India

Corresponding Author: Syed N Basheer, Department of Conservative Dentistry and Endodontics, Faculty of Dentistry, Maharaj Vinayak Global University, Jaipur, India, Phone: +91 9902992136, e-mail: drsyedmds@gmail.com

How to cite this article: Basheer SN, Sharma DK. Antimicrobial Efficacy of a Novel Irrigant, Nigella-Eugenia Oil Composite against Enterococcus faecalis and Candida albicans. World J Dent 2022;13(2):96-103.

Source of support: $\mathrm{Nil}$

Conflict of interest: None

neutralize necrotic tissues and completely remove pulpal remnants and predentin on the instrumented surfaces. ${ }^{12}$ Although it confers many advantageous properties, at higher concentrations it causes ulceration, hemolysis, and necrosis outside the confines of root canals and may injure periapical tissues. ${ }^{13}$ Other known disadvantages include unpleasant taste, tendency to bleach clothes and, inability to remove the smear layer. ${ }^{14}$ Furthermore, there are some debates about its antibacterial activity at lower concentrations, which are promoted as a way to reduce harmful reactions. ${ }^{15}$

Chlorhexidine (CHX) gluconate, a cationic bisbiguanide, is often suggested as an irrigant in endodontics for its antibacterial effects and substantivity, which permits it to reside attached to different

(c) The Author(s). 2022 Open Access This article is distributed under the terms of the Creative Commons Attribution 4.0 International License (https://creativecommons. org/licenses/by-nc/4.0/), which permits unrestricted use, distribution, and non-commercial reproduction in any medium, provided you give appropriate credit to the original author(s) and the source, provide a link to the Creative Commons license, and indicate if changes were made. The Creative Commons Public Domain Dedication waiver (http://creativecommons.org/publicdomain/zero/1.0/) applies to the data made available in this article, unless otherwise stated. 
tissues and provide a long-lasting antibacterial activity of 8 to $12 \mathrm{~h} .{ }^{16}$ Chlorhexidine gluconate is known to have lower cytotoxicity than $\mathrm{NaOCl}$. Chlorhexidine, on the contrary, can only be used as an auxiliary irrigant or a final rinse, according to research, and is not a suitable substitute for $\mathrm{NaOCl} .{ }^{17}$ Despite the fact that $\mathrm{CHX}$ is less caustic than $\mathrm{NaOCl}$, it has been known to cause skin irritation. ${ }^{18}$ Furthermore, its ability to inhibit the regeneration capability of periapical tissues may be shown by its cytotoxic effects on human osteoblasts. ${ }^{19}$

As all the chemical root canal irrigants have some limitations, the search for an ideal root canal irrigant still continues. Use of traditional herbal medicines in the past has shown antimicrobial properties, together with their nontoxic nature and lesser cost they can be an ideal root canal irrigant of choice. Thus, the aim of developing nontoxic herbal irrigants with antimicrobial activity against the endodontic microorganisms is highly significant.

Nigella sativa is an annual herb of the Ranunculaceae family also called as black seed or black cumin which grows in countries bordering the Mediterranean Sea, Pakistan, and India. The black cumin seeds contain many pharmacologically active constituents like thymoquinone (TQ), dithymoquinone, thymol, and thymohydroquinone. ${ }^{20}$

Eugenia caryophyllus are native to the Maluku Islands in Indonesia. Its common name is clove, commercially harvested in India, Indonesia, Sri Lanka, and Africa. ${ }^{21}$ The clove bud oil consists of eugenol, beta-caryophyllene, rhamnetin, crategolic acid, kaempferol, and eugenitin. ${ }^{22}$ These compounds have wide range of medicinal value that attributes in the treatment of dental diseases.

No published studies have assessed antimicrobial effect of combination of N. sativa and E. caryophyllus against E. faecalis and C. albicans. Hence in the present research, the aim is to combine $N$. sativa and E. caryophyllus and make a novel natural irrigant called Nigella-Eugenia oil composite (NEOc) and check its antimicrobial effect on E. faecalis and C. albicans and compare against standard root canal irrigants like $2 \% \mathrm{CHX}$ and $2.5 \% \mathrm{NaOCl}$.

\section{Materials and Methods}

The current study was conducted at Ramakrishna College of Arts and Science in Coimbatore, Tamil Nadu, India, in the Department of Microbiology. The work was completed between December 2018 and March 2020.

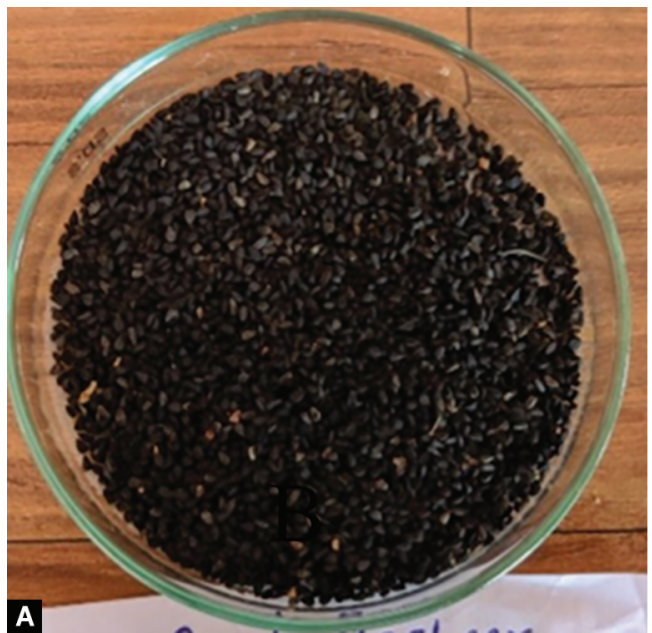

Figs 1 A and B: (A) Nigella sativa (NS), (B) Eugenia caryophyllus (EC)

\section{Collection of Nigella sativum and Eugenia caryophyllus}

N. sativum (Fig. 1A) and E. caryophyllus (Fig. 1B) were collected from the farmhouse, Tamil Nadu Agricultural University, Coimbatore, Tamil Nadu, India. The Nigella seeds and Eugenia cloves were prewashed in deionized water and kept under shade until completely dried for milling.

\section{Sample Preparation-Drying and Milling}

$N$. sativa fried seeds $(100 \mathrm{~g})$ and $100 \mathrm{~g}$ of cloves were arranged separately in aluminum trays and oven dried at 40 to $50^{\circ} \mathrm{C}$ for $2 \mathrm{~h}$ until the moisture content reach $<10 \%$. The dried parts were grounded to powder and sieved using metal sieve. Sieved particles were stored at room temperature prior to testing.

\section{Procurement of Enterococcus faecalis and Candida albicans}

The challenge test organisms (E. faecalis and C. albicans) were procured from Microbiological Laboratory, Coimbatore, Tamil Nadu, India.

\section{Soxhlet Extraction-Nigella sativum and Eugenia caryophyllus}

For the present study, Soxhlet method which follows the principle of infusion method was chosen to extract the content from the given herbs. Finely milled $N$. sativum powder was placed in a porous bag or "thimble" which was made from cellulose paper and placed in the thimble chamber of the Soxhlet apparatus in the Soxhlet extraction procedure. The extraction solvent was heated in the bottom flask, and vaporized in the sample thimble, and condensed in the condenser before dripping back into the flask. The liquid content was drained back into the bottom flask when it reaches the siphon arm, and the procedure was repeated. In the Soxhlet extractor, powdered $N$. sativum plants were placed in a thimble. The extractor was filled with an ethanol solvent solution, and the temperature was set at $60^{\circ} \mathrm{C}$ and maintained for 6 hours.

Slowly and steadily the temperature was increased up to $100^{\circ} \mathrm{C}$. The extract from the thimble was collected in the round bottom flask, kept in the heating mantle below by passing through a side arm tube. Similar experimental set up was carried out for E. caryophyllus powdered samples. N. sativa $(50 \mathrm{~mL})$ and $50 \mathrm{~mL}$ of E. caryophyllus was extracted separately and taken in a separating funnel and stored at room temperature prior to testing.

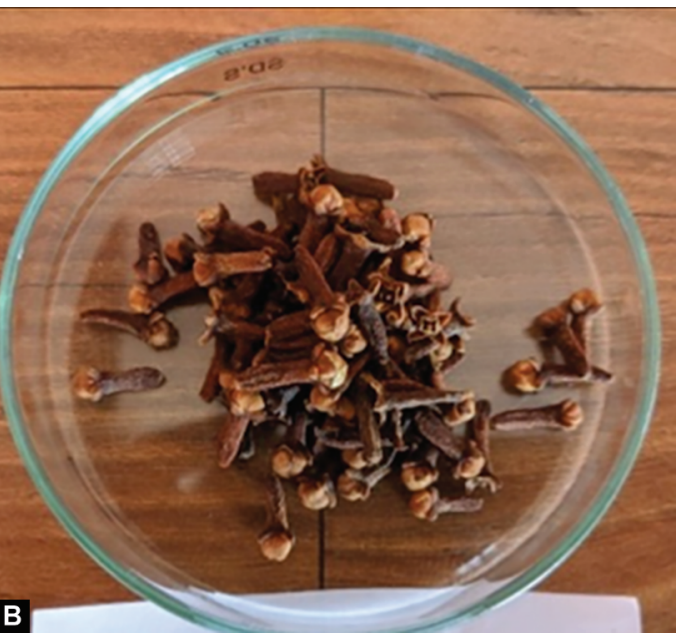




\section{Minimal Inhibitory Concentration, Minimal Bactericidal and Fungicidal Concentration}

Minimum inhibitory concentration (MIC) of $N$. sativa and E. caryophyllus (ethanol extracts) was determined by standard agar well diffusion method. The test organisms E. faecalis and C. albicans were grown in $5 \mathrm{~mL}$ of sterile nutrient broth (composition $\mathrm{g} / \mathrm{L}$ : peptone: $5 \mathrm{~g}$; yeast extract: $5 \mathrm{~g}$, beef extract: $3 \mathrm{~g}$, sodium chloride: $5 \mathrm{~g}$; Final $\mathrm{pH}-7.0 \pm 0.2$ ) for $24 \mathrm{~h}$ at $37^{\circ} \mathrm{C}$. The growth of the organism was measured based on the turbidity in the test culture tubes. The turbidity of microbial suspension was compared and adjusted to 0.5 on the Mc Farland scale. To determine the MIC of N. sativa and E. caryophyllus, a set of Mueller-Hinton broth tubes (five tubes) were prepared under sterile conditions for each test organism. About $100 \mu \mathrm{L}$ of extracted $N$. sativa and $100 \mu \mathrm{L}$ E. caryophyllus separately at different concentrations $(100,200,300,400$, and $500 \mu \mathrm{g} / \mathrm{mL}$ ) was added to each Mueller-Hinton broth tubes. Followed by about $10 \mu \mathrm{L}$ of test culture suspension (E. faecalis and C. albicans) was added to the broth separately and observed for turbid growth. All the tubes were incubated for $24 \mathrm{~h}$ at $37^{\circ} \mathrm{C}$. The lowest dilution inhibiting the growth of test organism was selected as the MIC of N. sativa and E. caryophyllus.

To determine the minimal bactericidal and fungicidal concentration (MBC/MFC) of the $N$. sativa and $E$. caryophyllus extracts, a loopful of sample was taken from the selected MIC tube of respective organism and inoculated onto Mueller-Hinton agar (MHA) plates (composition $\mathrm{g} / \mathrm{L}$ acid hydrolysate of casein: $17.5 \mathrm{~g}$; starch: $1.5 \mathrm{~g}$, sodium chloride: $5.0 \mathrm{~g}$, agar $17.0 \mathrm{~g}$; final $\mathrm{pH}-7.0 \pm 0.2$ ). All the plates were incubated and observed for the absence of growth determining the MFCand MBC of the selected herbal extracts.

\section{Preparation of Nigella-Eugenia Oil Composite}

Using N. sativum and E. caryophyllus ethanol extracts, an herbal composite (NEOc) was developed. Briefly, $10 \mathrm{~mL}$ of $N$. sativum extracts was kept under stirring conditions using a magnetic stirrer $\left(180 \mathrm{rpm}, 40^{\circ} \mathrm{C}\right)$ in a beaker. Followed by adding $10 \mathrm{~mL}$ of $E$. caryophyllus extracts dropwise onto the above extract at the rate of $1 \mathrm{~mL}$ per minute. The magnetic stirring condition was kept constant for $2 \mathrm{~h}$ till complete development of composite. Developed NEO composites $(20 \mathrm{~mL}$ ) were stored in brown, amber bottle at refrigeration temperature prior to antibacterial activity and other tests.
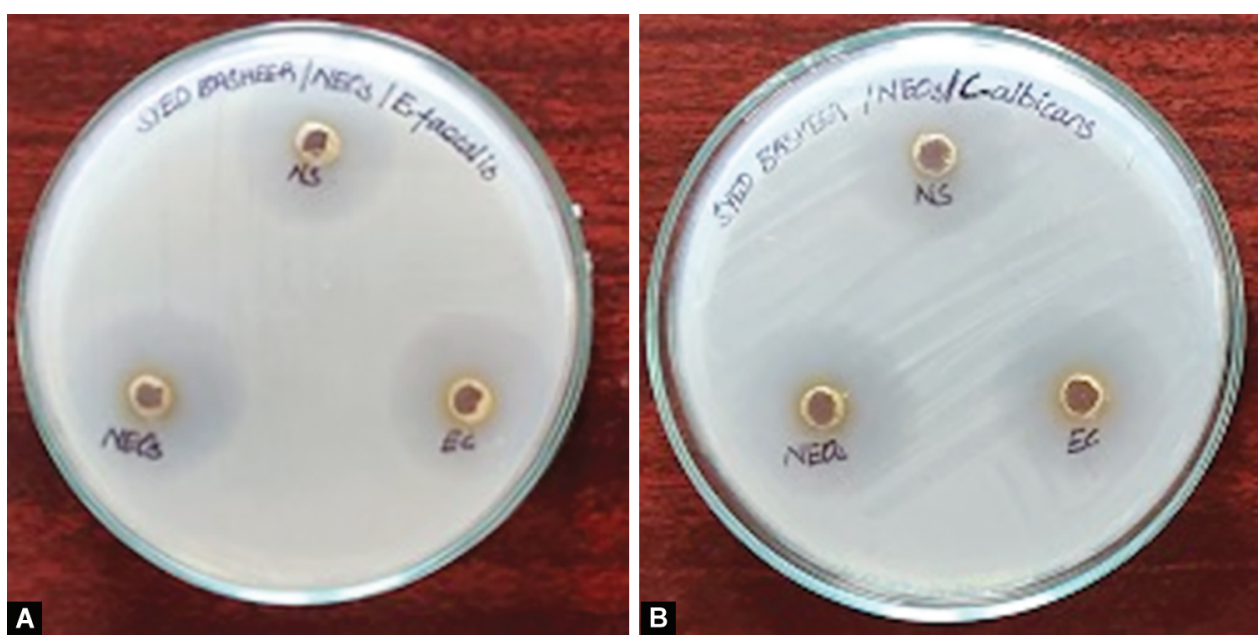

Figs 2A and B: Antimicrobial activity of the Nigella sativa (NS), Eugenia caryophyllus (EC), and Nigella-Eugenia composite (NEOc) against (A) Enterococcus faecalis and (B) Candida albicans

\section{Antimicrobial Activity of Herbal Irrigants}

The antimicrobial activity of N. Sativa, E. caryophyllus extracts, and NEOc was evaluated against the test organisms by well diffusion method. Two sterile MHA (composition $\mathrm{g} / \mathrm{L}$ acid hydrolysate of casein: $17.5 \mathrm{~g}$; starch: $1.5 \mathrm{~g}$, sodium chloride: $5.0 \mathrm{~g}$, agar $17.0 \mathrm{~g}$; final $\mathrm{pH}(7.0 \pm 0.2)$ plates were prepared and allowed to solidify in one plate about $0.1 \%$ inoculum suspension of $E$. faecalis and in another plate same amount of inoculum suspension of $C$. albicans was swabbed uniformly over the agar surface. Under sterile conditions, three $6 \mathrm{~mm}$ wells were cut on the agar surface of each MHA plate. About $20 \mu \mathrm{L}$ of $N$. sativa, $20 \mu \mathrm{L}$ E. caryophyllus extracts and $20 \mu \mathrm{L}$ of the developed NEO composite was loaded in the MHA plate inoculated with $E$. faecalis, similarly the MHA plate inoculated with C. albicans also was loaded with the same amount of the herbal extracts in three $6 \mathrm{~mm}$ wells and both the plates were incubated at $37^{\circ} \mathrm{C}$ for $24 \mathrm{~h}$ (Fig. 2). The antimicrobial activity was evaluated in terms of zone of inhibition around the wells in both the inoculated MHA plates. The inhibition clear zones were measured and recorded in millimeter.

\section{Antimicrobial Activity of Chemical Irrigants}

In parallel the antimicrobial activity of $2.5 \% \mathrm{NaOCl}$ and $2 \% \mathrm{CHX}$ was evaluated against the test organisms by well diffusion method. Two sterile MHA (composition g/L acid hydrolysate of casein: $17.5 \mathrm{~g}$; starch: $1.5 \mathrm{~g}$, sodium chloride: $5.0 \mathrm{~g}$, agar $17.0 \mathrm{~g}$; final pH (7.0 \pm 0.2$)$ plates were prepared and allowed to solidify. About $0.1 \%$ inoculum suspensions of the test organism (E. fecalis and C. albicans) were swabbed uniformly over the agar surface separately. Under sterile conditions, $6 \mathrm{~mm}$ wells were cut on the agar surface of each MHA plates. About $20 \mu \mathrm{L}$ of of $2.5 \% \mathrm{NaOCl}$ and $20 \mu \mathrm{L}$ of $2 \% \mathrm{CHX}$ were loaded into the well and the plates were incubated at $37^{\circ} \mathrm{C}$ for $24 \mathrm{~h}$. The antimicrobial activity was evaluated in terms of zone of inhibition around the wells in all the inoculated MHA plates. The clear zones of inhibition were measured and reported in millimeters.

\section{Comparison of Antimicrobial Activity of Herbal and Chemical Irrigants}

The antimicrobial activity of $N$. sativa, E. caryophyllus, and NEOc was compared with $2.5 \% \mathrm{NaOCl}$ and $2 \% \mathrm{CHX}$ using the zone of inhibition values calculated against the test organisms $E$. faecalis and C. albicans. 


\section{In Vitro Biocompatibility of NEOc Using Standard MTT Assay Methods}

Cytotoxicity assay was used to evaluate the in vitro cytotoxicity. $\mathrm{L}_{929}$ fibroblast cell line used to evaluate cytotoxicity of NEOc.

To achieve confluence growth, the fibroblast cell lines were grown in 12-well microtiter plates. The composite sample was directly applied to the fibroblast monolayer that had formed. The plates were prewetted in a $70 \%$ aqueous ethanol solution for 48 hours before cell seeding, then washed twice with ultrapure water. The specimens were subsequently seeded with 10,000 cells per well of the L929 fibroblast cell line, as per standard cell culture procedures. For 15 days, the plates were incubated at $37^{\circ} \mathrm{C}$ with $5 \%$ $\mathrm{CO}_{2}$. The photometric MTT test was used to assess the influence of composite on fibroblast biocompatibility.

Samples were obtained from the 24-well plates at each time point and transferred to new plates for the MTT analysis. The MTT solution was prepared by dissolving the powder in phosphate-buffered saline at a concentration $1 \mathrm{mg} / \mathrm{mL}$. After $1 \mathrm{~h}$ of incubation, the purple crystals were dissolved by adding sodium dodecylsulfate (SDS) in a 1:1 mixture of water and dimethyl formamide (DMF) at a concentration of $20 \% \mathrm{w} / \mathrm{v}$. After adding $1 \mathrm{~mL}$ of MTT medium $(0.0005 \mathrm{mg} / \mathrm{mL})$ to each well, the plates were incubated for $3 \mathrm{~h}$, rinsed and desorbed in $100 \mu \mathrm{L}$ of $70 \%$ isopropanol. After being agitated rapidly at $400 \mathrm{rpm} / \mathrm{min}$ for $40 \mathrm{~min}$, the dyed medium was transferred to $96-$ well plate, and read at $550 \mathrm{~nm}$. The biocompatibility or cell viability is expressed as a percentage of the control sample (100\%)

\section{Results}

\section{Minimal Inhibitory Concentration and Minimal Bactericidal/Fungicidal Concentration}

Minimal inhibitory concentration and MBC/MFC of $N$. sativa and $E$. caryophyllus extracts were analyzed against $E$. faecalis and $C$. albicans. Among the four test concentrates of $N$. sativa, $300 \mu \mathrm{g} / \mathrm{mL}$ was found to be the MIC and MBC/MFC value for $E$. faecalis and C. albicans. In Table 1 the MIC and MBC/MFC of $N$. sativa was presented, respectively. Absence of growth in the respective tubes and plates determined the MIC and MBC/MFC values of $N$. sativa extracts against the test organisms. Similar results were found evident for $E$. caryophyllus extracts against the $E$. faecalis and
C. albicans. About $300 \mu \mathrm{g} / \mathrm{mL}$ of test concentrate was selected as the MIC and MBC/MFC value for the test organism. Absence of growth in the respective tubes and plates determined the MIC and MBC/MFC values of $E$. caryophyllus extracts against the test organisms (Table 2).

\section{Antimicrobial Activity of Herbal Irrigants}

The antimicrobial activity of the N. sativa, E. caryophyllus, and Nigella-Eugenia composite (NEOc) against E. faecalis and C. albicans were compared with $2.5 \% \mathrm{NaOCl}$ and $2 \% \mathrm{CHX}$ in the present study. The comparison was carried out to determine whether the synergistic effect of composite and the individual effect of plant extracts was significant in retarding the growth of dental pathogens in comparison with the efficacy of chemical irrigants.

About 18 and $19 \mathrm{~mm}$ of inhibitory zones were obtained for the ethanol extracts of $N$. sativa against $E$. faecalis and C. albicans. Almost similar size of inhibitory zones ( 17 and $19 \mathrm{~mm}$ ) were recorded for the ethanol extracts of $E$. caryophyllus against the respective test organisms. However the antimicrobial activity of the developed NEOc was found higher in terms of inhibitory zones than the individual plant extracts. The zone of inhibition for the NEOc against E. faecalis was $21 \mathrm{~mm}$ and against C. albicans was $22 \mathrm{~mm}$.

\section{Antimicrobial Activity of Chemical Irrigants}

Antimicrobial activity of chemical irrigants against $E$. faecalis and C. albicans was tested separately for $2.5 \% \mathrm{NaOCl}$ and $2 \% \mathrm{CHX}$ (Fig. 3). About 17 and $19 \mathrm{~mm}$ inhibitory zones were obtained for the irrigant $2.5 \% \mathrm{NaOCl}$ against E. faecalis and C. albicans, respectively. Inhibitory zones of about 19 and $20 \mathrm{~mm}$ were found evident against the respective test organisms for the other chemical irrigant $2 \% \mathrm{CHX}$.

\section{Comparison of Antimicrobial Activity between Herbal and Chemical Irrigants}

The inhibitory zones of the developed NEOc were about 21 and $22 \mathrm{~mm}$ against $E$. faecalis and C. albicans, respectively. The inhibitory zones of NEOc were higher relatively when compared with the inhibitory zones of individual plant extracts and individual chemical irrigants. The comparison of antimicrobial activity of the N. sativa, E. caryophyllus, and $\mathrm{NEOc}$ with $2.5 \% \mathrm{NaOCl}$ and $2 \% \mathrm{CHX}$ is presented in Figure 4.

Table 1: Minimal inhibitory concentration of Nigella sativa against Enterococcus faecalis and Candida albicans

\begin{tabular}{|c|c|c|c|c|c|c|}
\hline \multirow[b]{2}{*}{ S. No. } & \multirow[b]{2}{*}{ Test organism } & \multicolumn{5}{|c|}{ Presence or absence of growth } \\
\hline & & 1 & 2 & 3 & 4 & 5 \\
\hline 1 & Enterococcus faecalis & + & + & - & - & - \\
\hline 2 & Candida albicans & + & + & - & - & - \\
\hline
\end{tabular}

+ Presence of microbial growth, -Absence of microbial growth

1: $100 \mu \mathrm{g} / \mathrm{mL}, 2: 200 \mu \mathrm{g} / \mathrm{mL}, 3: 300 \mu \mathrm{g} / \mathrm{mL}, 4: 400 \mu \mathrm{g} / \mathrm{mL}, 5: 500 \mu \mathrm{g} / \mathrm{mL}$

Table 2: Minimal inhibitory concentration of Eugenia caryophyllus against Enterococcus faecalis and Candida albicans

\begin{tabular}{lllllll}
\hline & \multicolumn{7}{l}{ Presence or absence of growth } \\
\cline { 3 - 7 } S. No. & Test organism & 1 & 2 & 3 & 4 & 5 \\
\hline 1 & Enterococcus faecalis & + & + & - & - & - \\
2 & Candida albicans & + & + & - & - & - \\
\hline
\end{tabular}

+ Presence of microbial growth, - Absence of microbial growth

1: $100 \mu \mathrm{g} / \mathrm{mL}, 2: 200 \mu \mathrm{g} / \mathrm{mL}, 3: 300 \mu \mathrm{g} / \mathrm{mL}, 4: 400 \mu \mathrm{g} / \mathrm{mL}, 5: 500 \mu \mathrm{g} / \mathrm{mL}$ 

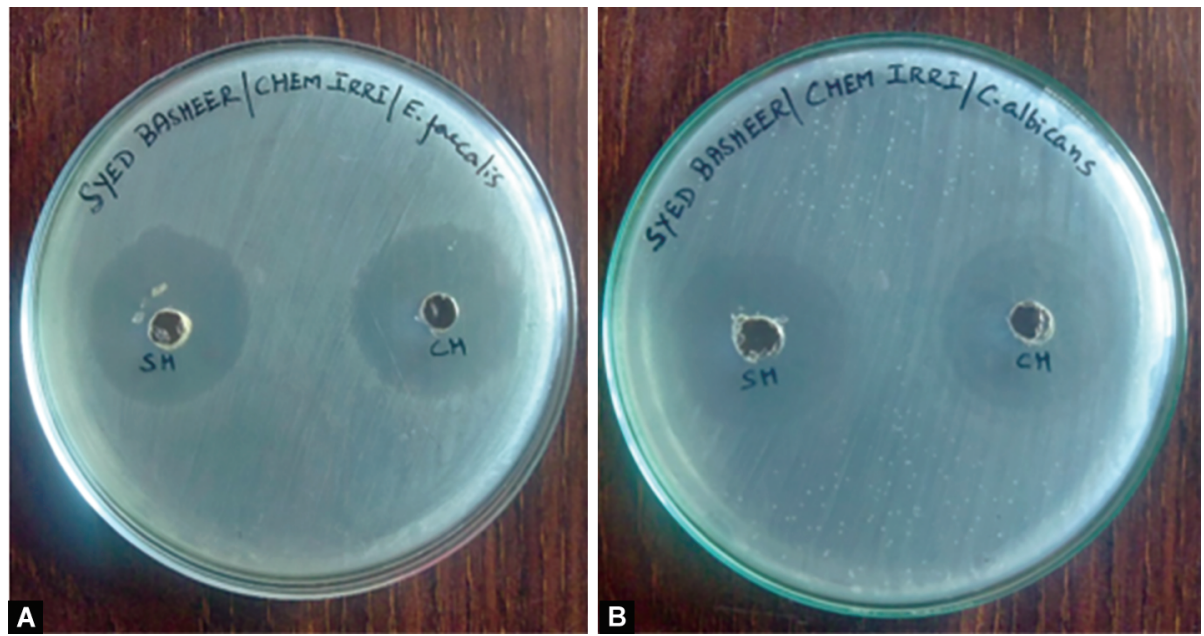

Figs $3 \mathrm{~A}$ and B: Antimicrobial activity of sodium hypochlorite $(\mathrm{SH})$ and chlorhexidine (CHX) against (A) Enterococcus faecalis; (B) Candida albicans

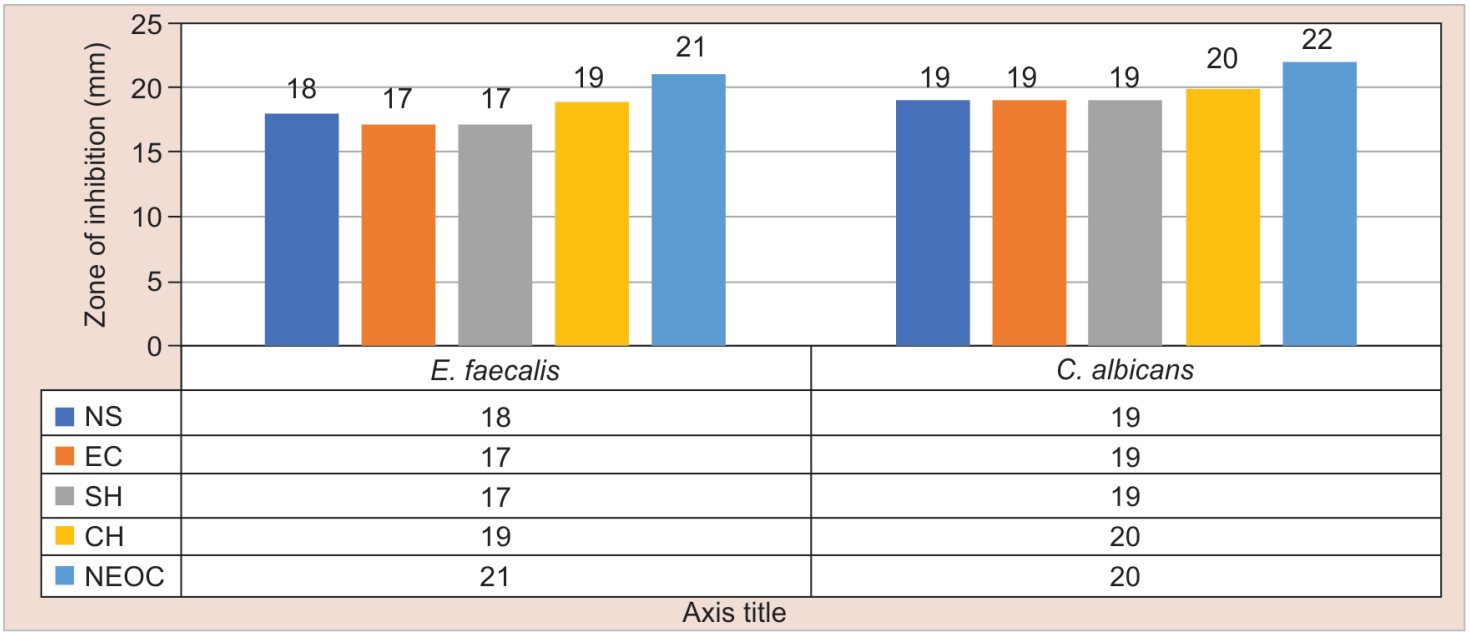

Fig. 4: Graphical representation of antimicrobial activity of herbal and chemical irrigants

\section{In Vitro Biocompatibility of NEOc Using Standard MTT Assay Methods}

The biocompatibility of the developed NEOc was investigated using standard MTT assay method. During the analysis, the cell viability percentage was more than $99 \%$ for all the test concentrations indicating the biocompatibility of the NEOc (Table 3). In addition, no cytotoxicity was evident on the developed $L_{929}$ fibroblast cells.

The biocompatibility of the developed NEOc was investigated using standard MTT assay method. As the cell viability percentage was found highly significant (>99\%) for all the test concentrate, the biocompatibility of the developed composite was thus proved evident.

\section{Discussion}

Bacteria such as E. faecalis and C. albicans have been associated with cases of endodontic treatment failure. the existing chemical endodontic irrigants used against these bacteria are $\mathrm{NaOCl}$ and $\mathrm{CHX}$. Sodium hypochlorite has some disadvantages such as unpleasant taste, tendency to bleach, and soft tissue inflammation when it is passed outside the confines of root canal, ${ }^{23}$ and $\mathrm{CHX}$ has cytotoxic effects on human osteoblasts when used as an irrigant, possibly indicating its ability to reduce the periapical tissues' regeneration capability, ${ }^{19}$ and also has been reported that it causes irritation to the skin. ${ }^{18}$

The search for an ideal root canal irrigant is continued to overcome the disadvantages of the existing endodontic irrigants and remove resistant bacteria from the root canal treatment and reduce the endodontic treatment failures. Irrigants made from natural sources has the potential to be ideal root canal irrigant because of its nontoxic nature, and its limited use against the antibiotic-resistant bacteria. Hence in the present study, based on the antimicrobial activity of N. sativa and E. caryophyllus extracts, specifically against dental infections a herbal composite was developed in the present study and termed as NEOc and tested whether the individual extracts or newly developed NEOc can be used as natural irrigants to combat against infection caused by $E$. faecalis and C. albicans.

The combination of two different herbal drugs were selected based on the character of synergism. Synergistic activity of drugs in a combination contains potential antimicrobial activity when compared to be tested alone. Mode of action of two different drugs on targeting the cellular components of a microbe influences more antimicrobial activity than the action of a single drug. Based on this synergistic character, $N$. sativa and E. caryophyllus are combined as a novel composite and antimicrobial activity against dental 
pathogens $E$. faecalis and C. albicans were studied in the present study.

Cytotoxicity assays are used commonly to evaluate the in vitro cytotoxicity. ${ }^{24}$ The biocompatibility of the developed NEOc was investigated using standard MTT assay method. During the analysis, the cell viability percentage was more than $99 \%$ for all the test concentrations indicating the biocompatibility of the NigellaEugenia oil composite. In addition, no cytotoxicity was evident on the developed $L_{929}$ fibroblast cells. However, some notable differences in cell morphology and appearance of few vacuoles (Fig. 5) have been found in the lower concentrates of composites (10 and $20 \mu \mathrm{g}$ concentrates). The appearance of these vacuoles may be due to the fusion of multiple membranes of fibroblast cells.

\section{Minimal Inhibitory Concentration and Minimal} Bactericidal/Fungicidal Concentration

Minimal inhibitory concentration and MBC/MFC of $N$. sativa and E. caryophyllus ethanol extracts were analyzed against $E$. faecalis and C. albicans. Among the four test concentrates of N. sativa and E. caryophyllus, $300 \mu \mathrm{g} / \mathrm{mL}$ was found to be the MIC and MBC/MFC value for E. faecalis and C. albicans. Similar works carried out by many researchers are discussed below which were found supportive to our present study.
Chaieb et al. reported the MIC value of $N$. sativa extract was found to be $32 \mu \mathrm{g} / \mathrm{mL}$ against $E$. faecalis. ${ }^{25}$ The MIC value of ethanol extracts of N. sativa in the present study was found to be $300 \mu \mathrm{g} / \mathrm{mL}$ against E. faecalis. MIC value obtained in Chaieb et al.'s work was found comparatively less ( $32 \mu \mathrm{g} / \mathrm{mL}$ ); this may be due to pure TQ compounds used rather than the crude extracts of $N$. sativa in the present study.

In another study, Aires et al. evaluated the bacteriostatic and bactericidal abilities of E. caryophyllus against oral bacteria in planktonic and biofilm states. The results obtained were promising, with best antibacterial activity against oral pathogen $E$. faecalis (MIC and $\mathrm{MBC}$ of $100 \mathrm{\mu g} / \mathrm{mL}){ }^{26}$ whereas in the present research it was $300 \mu \mathrm{g} / \mathrm{mL}$. The differences in the MBC and MIC values obtained in our study may be due to different factors such as methods adopted, source of E. caryophyllus used, and type of strains tested.

\section{Comparison of Antimicrobial Activity between Herbal and Chemical Irrigants}

The antimicrobial activities of the N. sativa, E. caryophyllus, and $\mathrm{NEO}$ against $E$. faecalis and C. albicans were compared with $\mathrm{NaOCl}$ and $\mathrm{CHX}$ in the present study. The comparison was carried out to determine whether the synergistic effect of composite and the individual effect of plant extracts was significant in retarding the

Table 3: Cytotoxicity analysis of Nigella-Eugenia oil composite (NEOc)

\begin{tabular}{llll}
\hline \multicolumn{5}{c}{$\begin{array}{l}\text { Fibroblast cell lines-MTT assay } \\
\text { concentration } \\
\text { S. No. }\end{array}$} & Cell viability (\%) & Cytotoxic reactivity \\
\hline 1 & 5 & $>99$ & No cytotoxicity \\
2 & 10 & $>99$ & No cytotoxicity \\
3 & 15 & $>99$ & No cytotoxicity \\
4 & 20 & $>99$ & No cytotoxicity \\
5 & 25 & $>99$ & No cytotoxicity \\
\hline
\end{tabular}

$5 \mu \mathrm{g}$

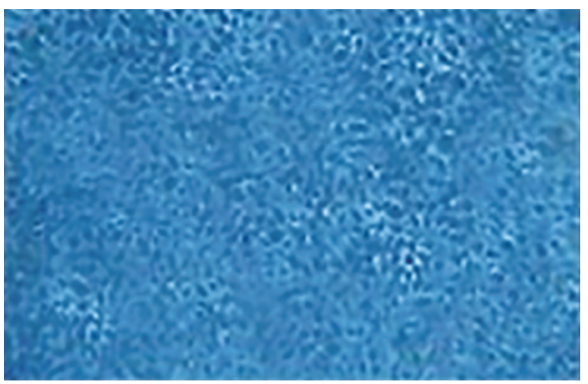

$20 \mu g$

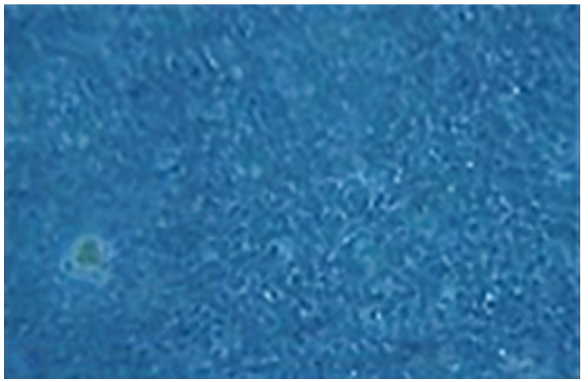

$10 \mu \mathrm{g}$

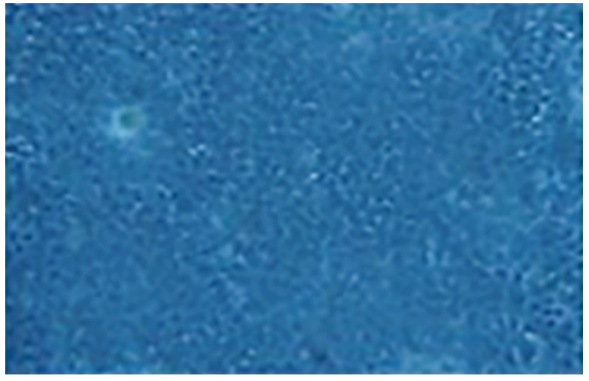

$25 \mu \mathrm{g}$

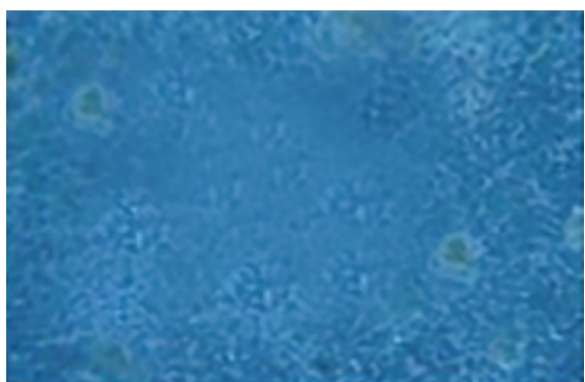

$15 \mu g$

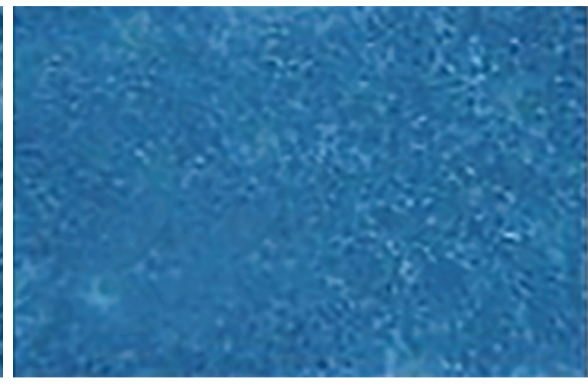

Control

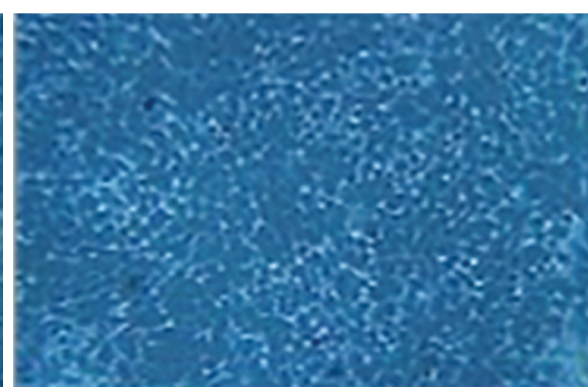

Fig. 5: Microscopic analysis of the biocompatibility of Nigella-Eugenia oil composite (NEOc) using MTT assay 
growth of dental pathogens in comparison with the efficacy of chemical irrigants. The inhibitory zones of N. sativa, E. caryophyllus, and NEOc showed promising results and the composite showed relatively more activity than individual herbs.

In the present study, the MIC and MBC/MFC values of ethanol extracts of $N$. sativa was found to be $300 \mu \mathrm{g} / \mathrm{mL}$ against $E$. faecalis and C. albicans, and about 18 and $19 \mathrm{~mm}$ of inhibitory zones were observed for the extracts of $N$. sativa against $E$. faecalis and C. albicans, respectively. Jain et al. in her study found that that $N$. sativa oil has an MIC of $0.4 \mu \mathrm{L} / \mathrm{mL}$ against . faecalis $^{27}$ and Hanafy and Hatem observed that mean diameter zone of inhibition in discs containing ether extract of $400 \mu \mathrm{g}$ nigella sativa on $\mathrm{MHA}$ plates inoculated with C. albicans was $2.1 \mathrm{~cm} .{ }^{28}$ Direct comparison of MIC, MBC/MFC could not be done from these studies, because of different methodology adopted. However, the results of both the previous studies were found to be supportive to our present research in terms of inhibitory action of $N$. sativa against $E$. faecalis and C. albicans.

In the present study, the MIC and MBC/MFC values of ethanol extracts of $E$. caryophyllus was found to be $300 \mu \mathrm{g} / \mathrm{mL}$ against E. faecalis and C. albicans, and about 17 and $19 \mathrm{~mm}$ of inhibitory zones were observed for the extracts of $E$. caryophyllus against E. faecalis and C. albicans, respectively. Silvestri et al. found that eugenol which is the major compound responsible for the antimicrobial activity of E. caryophyllus showed MIC and MBC of $1 \mu \mathrm{g} / \mathrm{mL}$ against $E$. faecalis. ${ }^{29}$ The findings of Silvestri et al. could not be compared with results of our study because of different methodology, but the findings of Silvestri et al.'s study were supportive to our present research findings in terms of antimicrobial activity of $E$. caryophyllus against $E$. faecalis.

Mohamed and Badri investigated antimicrobial activity of E. caryophyllus against C. albicans and observed $32 \mathrm{~mm}$ of zone of inhibition. ${ }^{30}$ The study of Mohamed and Badri was supportive to the present research in terms of inhibitory action of $E$. caryophyllus against $C$. albicans. However, the difference in the zone of inhibition can be because of the source of $E$. caryophyllus or its extraction method or different strains of $C$. albicans used in the study.

The antimicrobial activity of $\mathrm{NaOCl}(17$ and $19 \mathrm{~mm}$ ) and $\mathrm{CHX}$ (19 and $20 \mathrm{~mm}$ ) also revealed similar inhibitory zone size against E. faecalis and C. albicans when compared to the natural oil extracts. Jose et al. focused on the impact of microbes forming biofilm postendodontic treatment. Hence the researchers aimed to compare a commercial disinfectant, QMiX with chemical irrigants $(\mathrm{NaOCl}$ and $\mathrm{CHX}$ ) and natural irrigants (guava leaf extract, and $A$. vera extract) in terms of antimicrobial activity against $E$. faecalis. During this analysis, the researchers reported that all test solutions showed good antimicrobial activity against the test organism. ${ }^{31}$ In terms of antibacterial activity of $\mathrm{NaOCl}$ and $\mathrm{CHX}$ against $E$. faecalis, the work of Jose et al. was found to be supportive of our current research. Bidar et al. studied the comparative antimicrobial effect of $2 \% \mathrm{CHX}, 2.5 \% \mathrm{NaOCl}$, and MUMS containing $2 \% \mathrm{CHX}$ against C. albicans. The researchers revealed that chlorhexidinated MUMS showed antimicrobial effect like $\mathrm{CHX}$ solution. ${ }^{32}$ In our present study also $2 \% \mathrm{CHX}$ solution showed good antimicrobial effect in terms of zone of inhibition against $C$. albicans.

In the present research the antimicrobial activity of the developed NEOc expressed in terms of zone of inhibition was 21 and $22 \mathrm{~mm}$ against $E$. faecalis and $C$. albicans. The inhibition zones of $\mathrm{NEO} c$ were relatively higher than the individual plant extracts and the individual chemical irrigants. The combination of two different herbal drugs in the developed composite were selected based on the character of synergism. Synergistic activity of drugs in a combination contains potential antimicrobial activity in terms of mode of action on targeting the cellular components of a microbe to make it lethal than the action of a single drug. In accordance to literature survey, the mode of action of herbal extracts was described in terms of inhibitory activity on the microbial cells. The mode of action involves the lethal effect of herbal extracts on the cell membrane of organisms; active components of extracts and their hydrophobicity enable them to partition the lipids of the cell membrane, rendering them permeable and leading to leakage of cell contents, finally leading to cell lysis. ${ }^{33}$ The synergistic activity of two different herbal oil extracts in the developed composite was found evident in terms of antimicrobial activity when tested against $E$. faecalis and C. albicans.

\section{Limitations of the Present Study}

The present study is an in vitro study in which the conditions of the root canal has not been replicated, contact time for bactericidal action with the organisms has not been studied. Mechanism of action at cellular and molecular level should be determined and controlled preclinical and clinical trials should be conducted before NEOc can be recommended to be used alternatively with chemical irrigants during endodontic therapy.

\section{Conclusion}

This study highlighted the promising antimicrobial activity of a novel composite termed NEOc formulated by combining $N$. sativa and $E$. caryophyllus extracts against $E$. faecalis and C. albicans. Nigella-Eugenia oil composite exhibited maximum antimicrobial activity than the activity exerted by the herbs alone, thus conforming the synergism between two herbal extracts present in the developed composite. Nigella-Eugenia oil composite can be used as an alternative to chemical irrigants such as $\mathrm{NaOCl}$ and $\mathrm{CHX}$ after understanding its effectiveness in preclinical trials using simulated root canal conditions, and clinical trials with optimized parameters.

\section{References}

1. Nair PNR. On the causes of persistent apical periodontitis: a review. Int Endod J 2006;39(4):249-281. DOI: 10.1111/j.1365-2591.2006.01099.x

2. Sjögren $U$, Figdor $D$, Persson $S$, et al. Influence of infection at the time of root filling on the outcome of endodontic treatment of teeth with apical periodontitis. Int Endod J 1997;30(5):297-306. DOI: 10.1046/j.1365-2591.1997.00092.x

3. El Karim I, Kennedy J, Hussey D. The antimicrobial effects of root canal irrigation and medication. Oral Surg Oral Med Oral Pathol Oral Radiol Endod 2007;103(4):560-569. DOI: 10.1016/j.tripleo.2006.10.004

4. Pinheiro ET, Gomes BP, Ferraz CC, et al. Microorganisms from canals of root-filled teeth with periapical lesions. Int Endod J 2003;36(1):1-11. DOI: 10.1046/j.1365-2591.2003.00603.x

5. Gomes BPFA, Pinheiro ET, Gadê-Neto CR, et al. Microbiological examination of infected dental root canals. Oral Microbiol Immunol 2004;19(2):71-76. DOI: 10.1046/j.0902-0055.2003.00116.x

6. Siqueira JF, Rôças IN. Clinical implications and microbiology of bacterial persistence after treatment procedures. J Endod 2008;34(11):12911301.e3. DOI: 10.1016/j.joen.2008.07.028

7. Stuart CH, Schwartz SA, Beeson TJ, et al. Enterococcus faecalis: its role in root canal treatment failure and current concepts in retreatment. J Endod 2006;32(2):93-98. DOI: 10.1016/j.joen.2005.10.049

8. Möller AJ, Fabricius L, Dahlén G, et al. Influence on periapical tissues of indigenous oral bacteria and necrotic pulp tissue in monkeys. Scand J Dent Res 1981;89(6):475-484. DOI: 10.1111/j.1600-0722.1981. tb01711.x 
9. Ng RP-Y. Sterilization in root canal treatment: current advances. Hong Kong Dent J 2004;1:52-57. http://www.hkda.org/hkdj/V1/N2/ v1N2_P52_FA1.pdf

10. Siqueira JF, Rôças IN, Santos SR, et al. Efficacy of instrumentation techniques and irrigation regimens in reducing the bacterial population within root canals. J Endod 2002;28(3):181-184. DOI: 10.1097/00004770-200203000-00009

11. Torabinejad M, Shabahang S, Bahjri K. Effect of MTAD on postoperative discomfort: a randomized clinical trial. J Endod 2005;31(3):171-176. DOI: 10.1097/01.don.0000137642.50944.a2

12. Abuhaimed TS, Abou Neel EA. Sodium hypochlorite irrigation and its effect on bond strength to dentin. Biomed Res Int 2017;2017:1930360. DOI: $10.1155 / 2017 / 1930360$

13. Farook SA, Shah V, Lenouvel D, et al. Guidelines for management of sodium hypochlorite extrusion injuries. Br Dent J 2014;217(12):679-684. DOI: $10.1038 /$ sj.bdj.2014.1099

14. Retamozo B, Shabahang S, Johnson N, et al. Minimum contact time and concentration of sodium hypochlorite required to eliminate Enterococcus faecalis. J Endod 2010;36(3):520-523. DOI: 10.1016/j. joen.2009.12.005

15. Luddin N, Ahmed HM. The antibacterial activity of sodium hypochlorite and chlorhexidine against Enterococcus faecalis: areview on agar diffusion and direct contact methods. J Conserv Dent 2013;16(1):9-16. DOI: 10.4103/0972-0707.105291

16. Agrawal V, Rao MR, Dhingra $K$, et al. An in vitro comparison of antimicrobial effcacy of three root canal irrigants-BioPure MTAD, 2\% chlorhexidine gluconate and $5.25 \%$ sodium hypochlorite as a final rinse against E. faecalis. J Contemp Dent Pract 2013;14(5):842-847. DOI: $10.5005 /$ jp-journals-10024-1413

17. Mohammadi Z, Abbott PV. Antimicrobial substantivity of root canal irrigants and medicaments: a review. Aust Endod J 2009;35(3):131-139. DOI: 10.1111/j.1747-4477.2009.00164.x

18. Foulkes DM. Some toxicological observations on chlorhexidine. J Periodontal Res Suppl 1973;12:55-60. DOI: 10.1111/j.1600-0765.1973. tb02165.x

19. Lee TH, Hu CC, Lee SS, et al. Cytotoxicity of chlorhexidine on human osteoblastic cells is related to intracellular glutathione levels. Int Endod J 2010;43(5):430-435. DOI: 10.1111/j.1365-2591.2010.01700.x

20. Amin B, Hosseinzadeh H. Black cumin (Nigella sativa) and its active constituent, thymoquinone: an overview on the analgesic and anti-inflammatory effects. Planta Med 2016;82(1-2):8-16. DOI: $10.1055 / \mathrm{s}-0035-1557838$

21. Gaylor R, Michel J, Thierry D, et al. Bud, leaf and stem essential oil composition of Syzygium aromaticum from Madagascar, Indonesia and Zanzibar. Int J Basic Appl Sci 2014;3(3). DOI: 10.14419/ijbas.v3i3.2473

22. Batiha GE, Alkazmi LM, Wasef LG, et al. Syzygium aromaticum L. (Myrtaceae): traditional uses, bioactive chemical constituents, pharmacological and toxicological activities. Biomolecules 2020;10(2):202. DOI: 10.3390/biom10020202

23. Valera MC, Silva KC, Maekawa LE, et al. Antimicrobial activity of sodium hypochlorite associated with intracanal medication for Candida albicans and Enterococcus faecalis inoculated in root canals. J Appl Oral Sci 2009;17(6):555-559. DOI: 10.1590/s1678-77572009000600003

24. Al-Sheddi ES, Farshori NN, Al-Oqail MM, et al. Cytotoxicity of Nigella sativa seed oil and extract against human lung cancer cell line. Asian Pac J Cancer Prev 2014;15(2):5. DOI: 10.7314/apjcp.2014.15.2.983

25. Chaieb K, Kouidhi B, Jrah H, et al. Antibacterial activity of thymoquinone, an active principle of Nigella sativa and its potency to prevent bacterial biofilm formation. BMC Complement Alternat Med 2011;11(1):29. DOI: 10.1186/1472-6882-11-29

26. Aires A, Barreto AS, Semedo-Lemsaddek T. Antimicrobial effects of essential oils on oral microbiota biofilms: the toothbrush in vitro model. Antibiotics (Basel). 2020;10(1):21. DOI: 10.3390/antibiotics10010021

27. Jain N, Kirankumar N, Naik S, et al., (eds). A comparative study on antimicrobial efficacy of a novel irrigant, Nigella sativa oil against Enterococcus faecalis (ATCC 29212): a preliminary study 2019. DOI: 10.36348/SJODR.2019.v04i09.004

28. Hanafy M, Hatem M. Studies on the antimicrobial activity of Nigella sativa seed (black cumin). J Ethnopharmacol. 1991;34(2-3):275-278. DOI: 10.1016/0378-8741(91)90047-h

29. Silvestri JDF, Paroul N, Czyewski E, et al. Perfil da composição química e atividades antibacteriana e antioxidante do óleo essencial do cravo-da-índia (Eugenia caryophyllata Thunb). Revista Ceres 2010;57:589-594. DOI: doi.org/10.1590/S0034$737 \times 2010000500004$

30. Mohamed SG, Badri AM. Antimicrobial activity of syzygium aromaticum and citrus aurantifolia essential oils against some microbes in Khartoum, Sudan. EC Microbiol 2017;12:253-259. https:// www.ecronicon.com/ecmi/pdf/ECMI-12-00405.pdf

31. Jose J, Krishnamma S, Peedikayil F, et al. Comparative evaluation of antimicrobial activity of QMiX, $2.5 \%$ sodium hypochlorite, $2 \%$ chlorhexidine, guava leaf extract and Aloe vera extract against Enterococcus faecalis and Candida albicans: an in-vitro Study. J Clin Diagnc Res 2016;10(5):ZC20. DOI: 10.7860/jcdr/2016/17705.7747

32. Bidar M, Hooshiar S, Naderinasab M, et al. Comparative study of the antimicrobial effect of three irrigant solutions (chlorhexidine, sodium hypochlorite and chlorhexidinated MUMS). J Contem Dental Pract 2012;13(4):436-439. DOI: 10.5005/jp-journals-10024-1164

33. Javed A, Venkatesha RT, Sagar S, et al. In vitro evaluation of the synergistic antimicrobial effect of Boswellia sacra and Nigella sativa, essential oil on human pathogenic microbial strains. Am J Phytomed Clin Therap 2015;3(2):8. https://www.imedpub.com/articles/in-vitroevaluation-of-the-synergisticantimicrobial-effect-of-boswelliasacra-andnigella-sativa-essential-oil-on-humanpathogenic-m.pdf 